segment, and the posterodorsal portion of the head is much less deeply and extensively infuscated.

Described from four specimens taken by Mr. T. Fukai in the Saitama division of Japan.

\title{
OBSERVATIONS ON THE RELATION BETWEEN FLOWER COLOR AND INSECTS.
}

\author{
By E. M. East and R. W. Glaser.
}

Bussey Institution, Harvard University.

In 1909 a cross was made between the small red flowered Nicotiana forgetiana Hort (Sand) and Nicotiana alata Lk. and Otto var. grandiflora Comes, the large white N. affinis of horticulture, for the purpose of studying certain problems of heredity. About fourteen thousand plants of the second, third and fourth hybrid generation have been grown, and it has been established beyond a reasonable doubt that each plant is completely self-sterile though it crosses easily with any of its neighbors. Several hundred carefully controlled self-pollinations have not yielded a single seed, while histological studies have shown self-fertilization to be practically impossible. On the other hand, hundreds of artificial cross pollinations have yielded capsules full of seed in almost every instance, showing with what ease cross-fertilization takes place, for artificial pollination is usually not as successful as natural pollination. The fact that every capsule formed naturally on these plants must have resulted from a cross-pollination produced by an insect, serves to excuse our adding to the already huge literature on the relations between insects and plants. The sixteen different color forms that have segregated from the original cross permit observations on the percentage of flowers cross-fertilized and the selective value, if any, of distinct color varieties.

Our knowledge of the behavior of insects relative to flowers has been greatly extended during the past few years by the work of Plateau, Forel, Lovell, Grænicher and others, but it has resulted in that obscurity which precedes aggregation and precipitation by disclosing the marvelous complexity of the relation. The adjustment between certain insect forms and certain types of flowers is 
just as obvious now as when pointed out by Sprengel, but few entomologists or botanists will admit its adequate interpretation by the simple natural selection idea as believed by Hermann Müller and his followers who did not see the obstacles to this view as plainly as did Darwin.

The attitude of botanists has been affected chiefly by genetic investigation. Mendelian research and hypotheses regarding mutational evolution have at least gained a serious reconsideration of the origin, inheritance, and cause of survival of flower forms. Investigations on cross- and self-fertilization, by giving a clear and reasonable interpretation of the vigor of first generation hybrids and the converse-the apparent deterioration through inbreeding hybrids - have caused us to view mechanisms for crosspollination at a new angle. Self-pollination gives inherently stranger races (vigor not masked by heterozygosis) and insures reproduction, but practically precludes the trial of variations not of decisive value or of various recombinations of new variations with old characters. On the other hand, cross pollination, while permitting the survival of weak types through the vigor of heterozygosis, and while rendering reproduction more dubious, does assure a trial of all new variations in all the combinations possible in a mendelian sense.

The appreciation of the intricacy of the behavior of insects toward flowers is due primarily to the knowledge of insect sense organs, to the ingenuity of the experiments of animal psychologists, and to the passing of the tendency to interpret all the actions of the lower animals as tropisms.

For these reasons the question as to whether particular flower colors have a survival value due to the preference of certain insects for them, upon which we have gathered a few data, would probably be answered somewhat as follows by the majority of biologists. Excluding any question of olfactory sense, it may be assumed that insects perceive color differences from short distances but seldom if ever exercise a choice. Night flyers, of course, perceive white much more easily than colors. These conclusions are supported by the data in the following table: 


\begin{tabular}{c|c|c|c}
\hline \hline Flower color. & $\begin{array}{c}\text { Total number } \\
\text { of flowers on } \\
\text { 10 average plants. }\end{array}$ & $\begin{array}{c}\text { Total number } \\
\text { of flowers } \\
\text { fertilized. }\end{array}$ & $\begin{array}{c}\text { Per cent. of } \\
\text { flowers } \\
\text { fertilized. }\end{array}$ \\
\hline White......... & 18,035 & 7,052 & 39.10 \\
Yellow......... & 26,686 & 4,836 & 18.12 \\
Red.......... & 14,165 & 2,154 & 15.21 \\
Purple......... & 9,721 & 1,628 & 16.74 \\
\hline
\end{tabular}

Ten average plants of each of the four colors-white, yellow, red and purple-were selected at random. The total number of flowers produced on each color type during the flowering season (July 15 to October 15) was determined by counting the places on the racemes where flowers had been. The number of capsules present was assumed to be the number of flowers fertilized, although this count is not as accurate as the first by reason of the accidental loss of capsules. Long experience with Nicotianas, however, leads us to believe that this error is small.

The first point to be noted is the comparatively small percentage of cross-pollination by insects. Numerous experiments on artificial cross-pollination have shown that a very small amount of pollen causes normal development of the capsules, yet the yellow, red and purple types had only about 17 per cent. of their blossoms crossed. According to the table, the percentage of white flowers fertilized was more than twice as high as any of the colored types. The reason for this is obvious. From the beginning of the flowering period, about July 15, to the end period of summer heat, about September 15, the flowers opened at about $4 \mathrm{p} . \mathrm{m}$. and remained open until about 7.30 a.m. During the last month of flowering, the weather was so cool that the flowers also were open throughout the day. Nearly two thirds of the fertilizations occurred during the last month as could be determined by the positions of the flowers on the racemes. Furthermore the percentage of fertilizations on the white type during the last month was about the same as on the colored types. Roughly, one might say then that about 6 per cent. of the pollinations of the colored types were made by nightflyers (Sphingidæ, etc.), while during the same period these insects pollinated from 20 per cent. to 25 per cent. of the white type. In 
other words, there was a high rate of selection of white flowers during the period when the flowers were pollinated at night, but there was no selection of colors when daylight pollinations were made by the Hymenoptera and Diptera that frequented the plants.

\title{
PHILIPPINE MOSQUITOES.
}

\author{
By C. S. LudLow \\ Army Medical Museum, Washington, D. C. \\ Myzomyia flavirostris sp. nov.
}

Female: Head dark, covered with dark brown and white forked scales, and white long slender scales on the vertex, extending forward as a long tuft; antennæ brown, verticels and pubescence white, basal joint brown but not so dark as the cephalic scales; palpi dark brown the ultimate joint white, except, a very narrow brown basal band extending as a tiny brown band on the apex of the penultimate, a broad white band on the base of the penultimate and the apex of the following joint, the remainder of the organ dark brown, except a very narrow white band, at the preceding joint, very heavily scaled at the base; proboscis light scaled on the apical half, often not noticeable from the dorsal aspect, and always more marked on the ventral side, the proximal half dark brown, very heavily scaled at the base; clypeus dark brown; eyes dark brown.

Thorax: prothoracic lobes dark, with brown chætæ; mesonotum has the median third of a light brown, sometimes almost yellowish, covered with the fine tomentum so often found on Anophelines, and sparsely with golden brown hair-like scales, a well marked dark median line broadening so as to cover the "bare space," and in some specimens suggestions of other laterad dark lines, a bunch of long white slightly curved scalesextending over the nape; the lateral parts are a rich dark brown. Scutellum dark brown in the median portion lighter laterad; metanotum dark; pleuræ almost black. hairs.

The abdomen is very dark, almost black, with scattered brown to golden brown

Legs: the coxæ and trochanters are dark, covered with small dark scales and chætæ; femora of the fore legs light brown, tibiæ and tarsi darker brown, ungues simple; mid-femora light brown, the rest of the leg dark brown, but the terminal tarsal joint appearing fawn colored in some lights, ungues simple; hind femora light brown, tibiæ much darker, especially toward the apex, and some specimens showing a tiny white apical spot, all the tarsal joints brown, sometimes with a suggestion of apical light spots on the third and fourth joints.

Wings, clear, covered with brown and light yellow scales. The costa as a whole is dark with five small light spots, one at the apex of the first long vein; one, extending on the first long, about on a line with the base of the second posterior cell, the third, also extending on the first is well interior to a line through the base of the fork of the fifth long vein, and the last is a tiny spot between this and the root of the wing. The wing field has many small spots the third long vein is mostly light, 

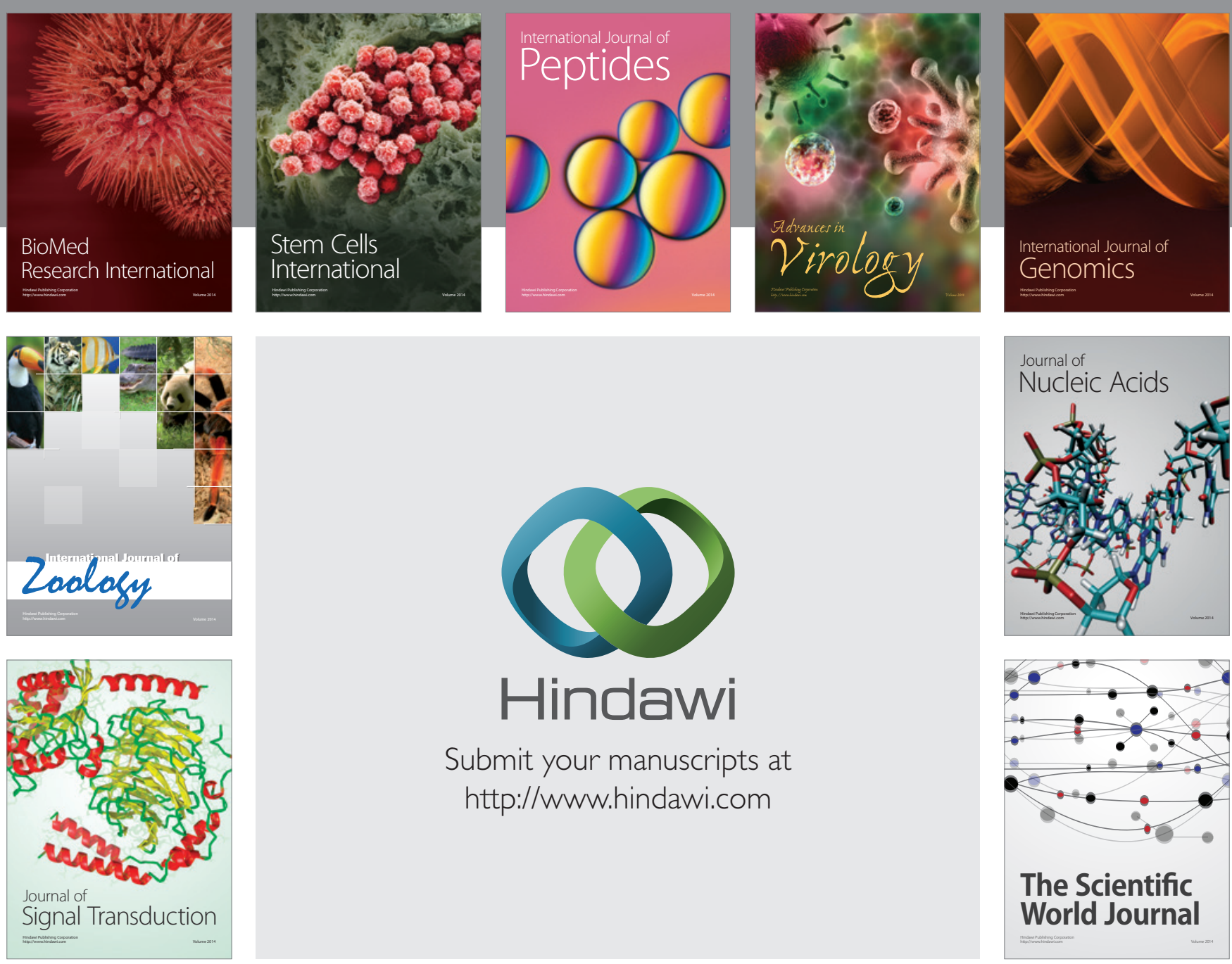

Submit your manuscripts at

http://www.hindawi.com
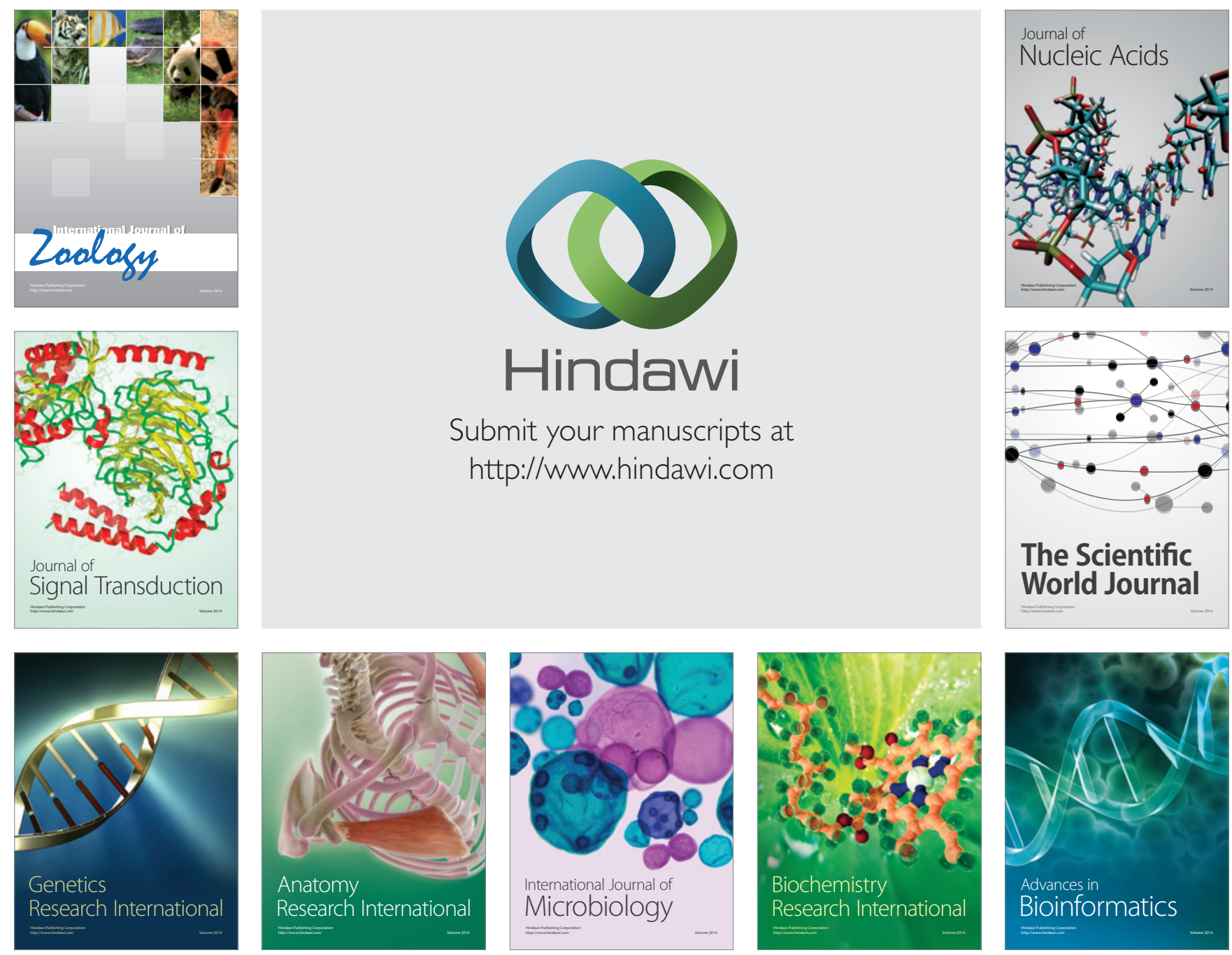

The Scientific World Journal
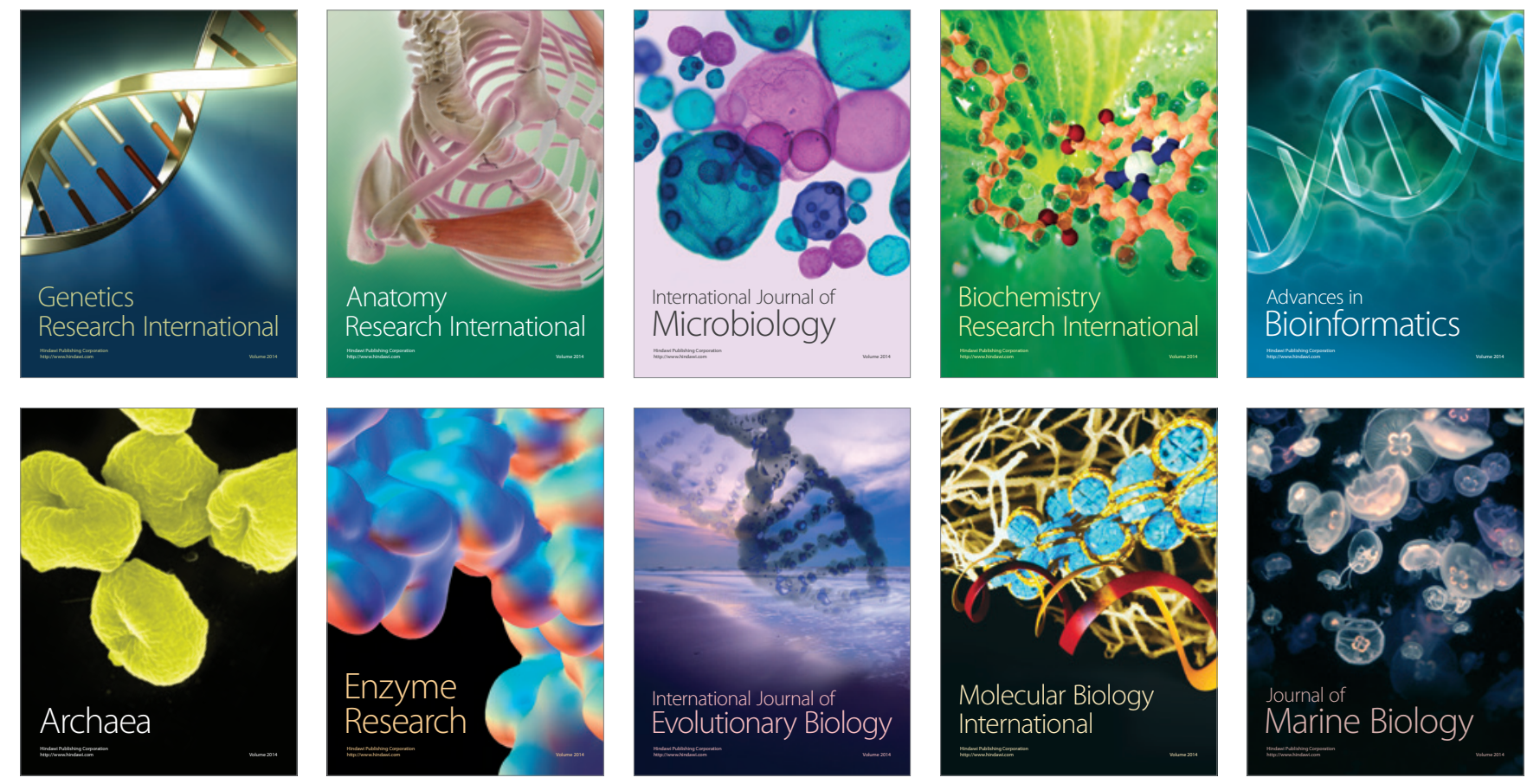